\title{
Reduced glucocorticoid sensitivity of monocyte interleukin-6 release in male employees with high plasma levels of tumor necrosis factor- $\alpha$
}

\author{
Petra H. Wirtz ${ }^{\mathrm{a}}$, Roland von Känel ${ }^{\mathrm{b}}$, Sabine Kunz-Ebrecht ${ }^{\mathrm{c}}$, \\ Ulrike Ehlert $^{\mathrm{a}}$, Joachim E. Fischer ${ }^{\mathrm{b}, *}$ \\ ${ }^{a}$ Department of Clinical Psychology and Psychotherapy, University of Zurich, Zürichbergstrasse 43, 8044 Zurich, Switzerland \\ ${ }^{\mathrm{b}}$ Institute for Behavioral Sciences, Swiss Federal Institute of Technology Zurich, Turnerstrasse 1, CH-8092 Zurich, Switzerland \\ ${ }^{\mathrm{c}}$ Department of Epidemiology \& Public Health, University College London, 1-19 Torrington Place, London WC1E 6BT, UK
}

\begin{abstract}
Cytokine production by monocytes plays a key role in atherosclerosis. In vitro, preincubation of whole blood with tumor necrosis factor (TNF)- $\alpha$ regulates interleukin (IL)-6 release from monocytes stimulated with lipopolysaccharide (LPS). We investigated whether plasma levels of TNF- $\alpha$ would also relate to LPS-stimulated monocyte IL-6 production and the inhibitory effect of a glucocorticoid on this process. 224 middle-aged men were assigned to three groups according to tertiles of plasma levels of TNF- $\alpha$. Subjects in the highest tertile (high TNF$\alpha, \mathrm{n}=75$ ) were compared to those in the lowest (low TNF- $\alpha, \mathrm{n}=74$ ) and medium tertile (medium TNF- $\alpha, \mathrm{n}=75$ ), respectively. In vitro monocyte IL-6 release following lipopolysaccharide (LPS)-stimulation was assessed with and without coincubation with incremental doses of dexamethasone. Monocyte glucocorticoid sensitivity was defined as the dexamethasone concentration inhibiting IL-6 release by 50\%. Subjects with high TNF- $\alpha$ showed more IL-6 release after LPS-stimulation than those with low TNF- $\alpha(\mathrm{p}=.011)$. Monocyte glucocorticoid sensitivity was lower in subjects with high levels of TNF- $\alpha$ than in subjects with low $(p=.014)$ and with medium $(p=.044)$ levels of TNF- $\alpha$. Results held significance when a set of classic cardiovascular risk factors was controlled for. Our findings suggest that elevated plasma levels of TNF- $\alpha$ might enhance LPS-stimulated IL-6 release from circulating monocytes. Such a mechanism might contribute to exaggerated monocyte cytokine release in vivo to any LPS-like danger signal such as related to an infection or cellular stress thereby promoting atherosclerosis.
\end{abstract}

(C) 2004 Published by Elsevier Inc.

Keywords: Cardiovascular disease; Cytokines; Inflammation; Monocytes; Glucocorticoid sensitivity

* Corresponding author. Tel.: +41-1-632-5831; fax: +41-1-632-1219.

E-mail address: fischer@ifv.gess.ethz.ch (J.E. Fischer). 


\section{Introduction}

Elevated plasma levels of the two proinflammatory cytokines tumor necrosis factor (TNF)- $\alpha$ and interleukin-6 (IL-6) have been repeatedly associated with increased risk for adverse cardiovascular outcomes (Elkind et al., 2002; Koukkunen et al., 2001; Plutzky, 2001; Ridker et al., 2000a,b; Rohde et al., 1999; Ross, 1999). Inflammatory processes in atherosclerosis are overtly mediated by monocytes which are an important source of circulating cytokines (Plutzky, 2001; Ross, 1999; Vaddi et al., 1994). The progression from early to more advanced stages of atherosclerosis hinges on the degree of inflammation within a lesion (Plutzky, 2001; Ross, 1999). Therefore, differences in monocyte inflammatory activity might contribute to increased coronary risk.

Regulatory processes in monocyte activation entail synthesis and release of proinflammatory cytokines as well as downregulation of cytokine release. While lipopolysaccharide (LPS) is one of the most potent activator of monocytes, endogenous glucocorticoids effectively downregulate monocyte cytokine production (Breuninger et al., 1993; Chrousos, 1995; Wick et al., 1993).

To investigate the effects of various conditions on monocyte activity, researchers have commonly used an in-vitro whole blood assay, assessing pro-inflammatory cytokine production after LPS stimulation and its suppression across a range of glucocorticoid concentrations (DeRijk et al., 1996, 1997; Rohleder et al., 2001). A recent in vitro study by Franchimont and coworkers following this method suggests that TNF- $\alpha$ modulates monocyte activity (Franchimont et al., 1999). In that study, preincubation of a whole-blood cell culture from ten healthy individuals with TNF- $\alpha$ resulted in decreased monocyte IL-6 production in response to LPS stimulation. Preincubation with TNF- $\alpha$ also resulted in a weaker dexamethasone-mediated IL-6 inhibition following LPS stimulation being compatible with reduced glucocorticoid sensitivity of monocytes (Franchimont et al., 1999).

In this study on a much larger sample size of a middle-aged working population, we hypothesized that basal levels of TNF- $\alpha$ in vivo would equally modulate monocyte IL-6 release following LPS stimulation in vitro. We further hypothesized that, in relation to basal TNF- $\alpha$ levels in vivo, different amounts of dexamethasone would be required to inhibit LPS stimulated monocyte IL-6 release. We wondered whether these hypotheses might hold even when established cardiovascular risk factors would be accounted for.

\section{Methods}

\section{Experimental subjects}

The study was part of a larger project as previously reported (Schnorpfeil et al., 2002). The ethic committee of the Swiss Federal Institute of Technology, Zurich, Switzerland, has formally approved the study protocol. A representative sample of 647 caucasian men and women from a total of 1760 employees of an airplane manufacturing plant in Southern Germany was invited. 325 subjects volunteered to participate and informed consent was obtained. Except from slightly higher age, there were no baseline demographic differences between volunteers and subjects who declined to participate (data not shown). In this study, we considered only men to avoid hormonal confounding 
of inflammatory activity by the female cycle. We excluded subjects who were on any hormone therapy, beta-blockers, psychoactive drugs, or steroids potentially affecting variables of interest. We also excluded subjects with self-reported history of previous cardiac surgery or percutaneous coronary angiography. This procedure left a study sample of 224 Caucasian men, whom we categorized into tertiles based on basal plasma TNF- $\alpha$ levels. In the following, we present comparisons between these three groups of individuals: 1) those in the first tertile ("low TNF$\alpha ", \mathrm{n}=74), 2$ ) those in the second tertile ("medium TNF- $\alpha$ ", $\mathrm{n}=75$ ), and those in the third tertile ("high TNF- $\alpha$ ", $n=75$ ) of basal unstimulated TNF- $\alpha$ levels. Table 1 provides health factors of participants.

\section{Experimental protocol}

Self-reported medical history and numbers of cigarettes smoked per day were assessed by a 96-item questionnaire with respective questions derived from the Nurses Health Study and the MONICA study (Jonsson et al., 1999; Michael et al., 1999). After having completed the questionnaire, subjects had a 15min rest period while sitting. Thereafter, blood pressure (BP) was determined twice within 5 min by sphygmomanometry. Also, subjects had their weight and height measured to compute body mass index (BMI). Within the following two weeks, all participants were rescheduled for blood collection on the second of two consecutive workdays and approximately two hours after awakening (i.e., between 6:30 am and 9:00 am) to avoid confounding of variables of interest by the circadian rhythm or by an antecedent day off.

Assays were started within five minutes from blood collection in a cell culture facility adjacent to the blood collection room. Blood was processed by standard techniques using cooled $\left(4^{\circ} \mathrm{C}\right)$ citrate tubes for the TNF- $\alpha$ assay. Urine collection for overnight cortisol secretion started at 9:00 $\mathrm{pm}$ the night before blood sampling, and it ended with the inclusion of the first void after awakening (Seeman et al., 1997).

Table 1

Health factors of men with low, medium, and high plasma levels of TNF- $\alpha$

\begin{tabular}{|c|c|c|c|c|}
\hline & $\begin{array}{l}\text { Low TNF- } \alpha \\
\text { Tertile } 1 \\
(\mathrm{n}=74)\end{array}$ & $\begin{array}{l}\text { Medium TNF- } \alpha \\
\text { Tertile } 2 \\
(\mathrm{n}=75)\end{array}$ & $\begin{array}{l}\text { High TNF- } \alpha \\
\text { Tertile } 3 \\
(\mathrm{n}=75)\end{array}$ & $\mathrm{P}$ \\
\hline $\mathrm{TNF}-\alpha[\mathrm{pg} / \mathrm{ml}]$ & $1.05 \pm 0.04$ & $1.74 \pm 0.02$ & $2.95 \pm 0.27$ & 0.000 \\
\hline Age [years] & $38.4 \pm 1.1$ & $41.2 \pm 1.0$ & $42.1 \pm 1.1$ & 0.030 \\
\hline Body mass index $\left[\mathrm{kg} / \mathrm{m}^{2}\right]$ & $25.40 \pm 0.3$ & $26.7 \pm 0.4$ & $27.3 \pm 0.5$ & 0.004 \\
\hline $\mathrm{LDL} / \mathrm{HDL}$ ratio & $2.78 \pm 0.10$ & $2.88 \pm 0.10$ & $3.30 \pm 0.12$ & 0.002 \\
\hline Systolic blood pressure $[\mathrm{mmHg}]$ & $128 \pm 1.5$ & $133 \pm 1.5$ & $135 \pm 2.4$ & 0.025 \\
\hline Diastolic blood pressure $[\mathrm{mmHg}]$ & $79.0 \pm 0.9$ & $84.1 \pm 1.1$ & $84.2 \pm 1.5$ & 0.002 \\
\hline Cigarettes/day & $6.7 \pm 1.2$ & $5.4 \pm 1.2$ & $6.6 \pm 1.2$ & N.S. \\
\hline Hemoglobin A1c [\%] & $5.16 \pm 0.04$ & $5.17 \pm 0.06$ & $5.15 \pm 0.06$ & N.S. \\
\hline Overnight urinary cortisol $[\mu \mathrm{g} / 1]$ & $46.9 \pm 2.9$ & $39.7 \pm 3.0$ & $44.1 \pm 5.4$ & N.S. \\
\hline Monocytes $\left[\times 10^{5} / \mathrm{ml}\right]$ & $5.88 \pm 0.22$ & $5.64 \pm 0.16$ & $6.21 \pm 1.8$ & N.S. \\
\hline
\end{tabular}

Values given are mean \pm SEM; HDL, high-density cholesterol; LDL, low-density cholesterol; TNF- $\alpha$, tumor necrosis factoralpha; N.S., not significant. 


\section{Biochemical analyses}

To measure plasma levels of TNF- $\alpha$ in vivo, we used a highly sensitive enzyme-linked immunosorbent assay (ELISA) (Quantikine HS, R\&D Systems Europe, Abington, United Kingdom). In vitro levels of IL-6 were determined using a commercially available ELISA kit (BD Pharmingen, San Diego, CA). Low-density lipoprotein (LDL) cholesterol, high-density lipoprotein (HDL) cholesterol, glycosylated hemoglobin A1c (HbA1c), and urinary cortisol were determined by a commercial laboratory (Synlab, Augsburg, Germany). Within three hours of blood sampling, monocyte counts were obtained from EDTA samples on the SE-9000 cell counter (Sysmex, Norderstedt, Germany).

\section{Glucocorticoid sensitivity assay}

Monocytes are the main cytokine producing cells in LPS-stimulated whole blood (Wright et al., 1990). To assess glucocorticoid sensitivity of stimulated cytokine production, dexamethasone has been widely used (DeRijk et al., 1996, 1997; Rohleder et al., 2001). Because of its link with cardiovascular endpoints (Yudkin et al., 2000), we chose to study IL-6 plasma concentrations. The whole blood cell culture is an in vitro method to analyze cytokine secretion in a controlled environment as well as to study the biological effects of drugs on cytokine release (De Groote et al., 1992, 1993). The whole blood assay avoids possible biases during stimulation of monocytes arising from pre-analytical steps by mononuclear cell separation, and it also preserves the "natural environment" (including hormones) of cytokine producing cells (De Groote et al., 1992; Elenkov et al., 2001).

In brief, the glucocorticoid sensitivity is assessed using a stimulant for cytokine release coincubated with incremental concentrations of a particular glucocorticoid. Following a defined incubation period, the cytokine content of the supernatant is determined. If a stimulant like LPS is used that predominantly activates monocytes, and if a cytokine like IL-6 is assessed, whose main source in whole blood are monocytes (DeRijk et al., 1996; Heinrich et al., 1990), one may be confident that the assay mainly reflects monocyte functioning.

The assay provides three endpoints: a) the cytokine release in response to LPS (without glucocorticoid coincubation), b) the characteristics of the inhibition curve plotting the cytokine concentrations against increasing glucocorticoid concentrations, and c) the estimated glucocorticoid concentration that exactly inhibits $50 \%$ of the LPS-stimulated cytokine release determined from a). The latter measure is independent of the absolute cytokine release, and it has been referred to as the $\mathrm{IC}_{50}-$ a single-measure index to describe the glucocorticoid sensitivity. To estimate $\mathrm{IC}_{50}$-values from the inhibition curve, we used a logistic curve fitting function.

In detail, the method was as follows: Venous blood was collected in heparinized tubes, diluted 1:10 with saline, and subsequently incubated with LPS (E. coli, 055:B5, no. L2880, Sigma-Aldrich Chemie GmbH, Steinheim, Germany). Dexamethasone (no. D8893, Sigma-Aldrich Chemie GmbH, Steinheim, Germany) was added at five different concentrations to a 24-well plate (no. 3047 Becton Dickinson, San Diego, California). LPS and dexamethasone then were dissolved in sterile saline solution ( $\mathrm{NaCl}$ 0,9\%, Fresenius Kabi, Stans, Switzerland). Diluted whole blood (400 $\mu$ l) was added to $50 \mu \mathrm{l}$ of LPS and to $50 \mu \mathrm{l}$ of various concentrations of dexamethasone. Final concentrations on

the plate were $15 \mathrm{ng} / \mathrm{ml}$ LPS and $0,10^{-10}, 10^{-9}, 10^{-8}$, and $10^{-7} \mathrm{~mol} / 1$ dexamethasone. Following a 6 h-incubation time at $37^{\circ} \mathrm{C}$ in $5 \% \mathrm{CO}_{2}$, plates were centrifuged for $10 \mathrm{~min}$ at $2000 \mathrm{~g}$ at $4{ }^{\circ} \mathrm{C}$ 
(DeRijk et al., 1997; Rohleder et al., 2001). The supernatant was collected and stored at $-80^{\circ} \mathrm{C}$ until assayed.

\section{Statistical analyses}

All calculations were performed using SPSS Inc. (10.0) and Curve Expert (1.3) software packages. Data are presented as means \pm SEM. Results were considered statistically significant at the $\mathrm{p} \leq .05$ level; all tests were two-tailed. If data were missing, cases were excluded listwise.

Across the three subject groups, univariate analyses of variance (ANOVAs) were calculated for health factors (Table 1). Univariate analyses of covariance were computed for LPS-stimulated IL-6 secretion, and $\mathrm{IC}_{50}$ values with the following seven established cardiovascular risk factors as covariates: age, BMI, $\mathrm{HbA1c}$, LDL/HDL ratio, systolic BP, diastolic BP, and number of cigarettes smoked per day. Repeated measure ANOVAs were applied to dose-response curves of dexamethasone-inhibition of LPS-induced IL-6 secretion with above listed risk factors being covariates. We applied Huynh-Feldt corrections for repeated measures. Because monocytes are the main source of cytokine release upon stimulation with LPS, whole blood IL-6 secretion was corrected for the monocyte count (Rohleder et al., 2001).

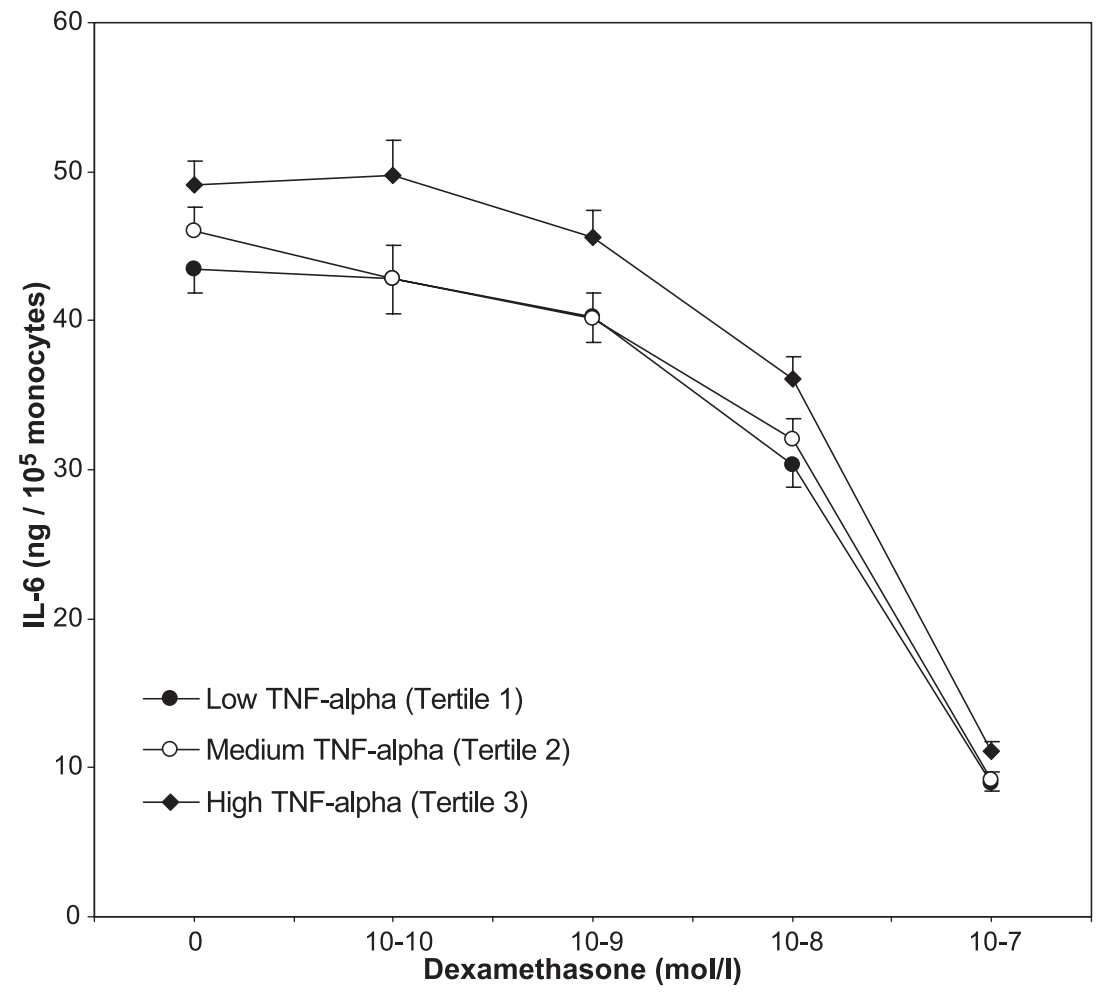

Fig. 1. LPS stimulated release of interleukin-6 (IL-6) and inhibition of IL-6 release by dexamethasone in the three groups (mean \pm SEM). Following LPS-stimulation, subjects with high levels of TNF- $\alpha$ produced more IL-6 than subjects with low TNF- $\alpha(\mathrm{p}=.011)$. When inhibited by increasing concentrations of dexamethasone, subjects with high plasma TNF- $\alpha$ levels produced more IL-6 than subjects with medium $(\mathrm{p}=.028)$ and with low $(\mathrm{p}=.010)$ TNF- $\alpha$ levels. 


\section{Results}

\section{Cardiovascular risk factors and health factors}

ANOVA revealed differences in terms of age, BMI, LDL/HDL cholesterol ratio, systolic BP, and diastolic BP across the three subject groups categorized as per high, medium and low plasma levels of TNF- $\alpha$ (Table 1). The observed relationship between TNF- $\alpha$ and cardiovascular risk factors prompted us to control for these risk factors in subsequent analyses. Consequently, all results reported in the following have been covaried by the aforementioned set of cardiovascular risk factors. Of note, lack of difference in overnight urinary cortisol excretion may indicate that subjects with differential plasma levels of TNF- $\alpha$ had equal activity of the hypothalamic-pituitary-adrenal axis.

\section{Stimulation of cytokine production}

After controlling for absolute monocyte counts, differences across groups in LPS-stimulated IL-6 release were significant $\left(\mathrm{F}_{2,180}=3.27, \mathrm{p}=.040\right.$; cardiovascular risk factors as covariates $)$. Post-hoc analyses revealed that men with high TNF- $\alpha$ had more LPS-stimulated IL-6 release than those with low TNF- $\alpha(\mathrm{p}=.011)$ (Fig. 1). IL-6 secretion was not significantly different between subjects with high

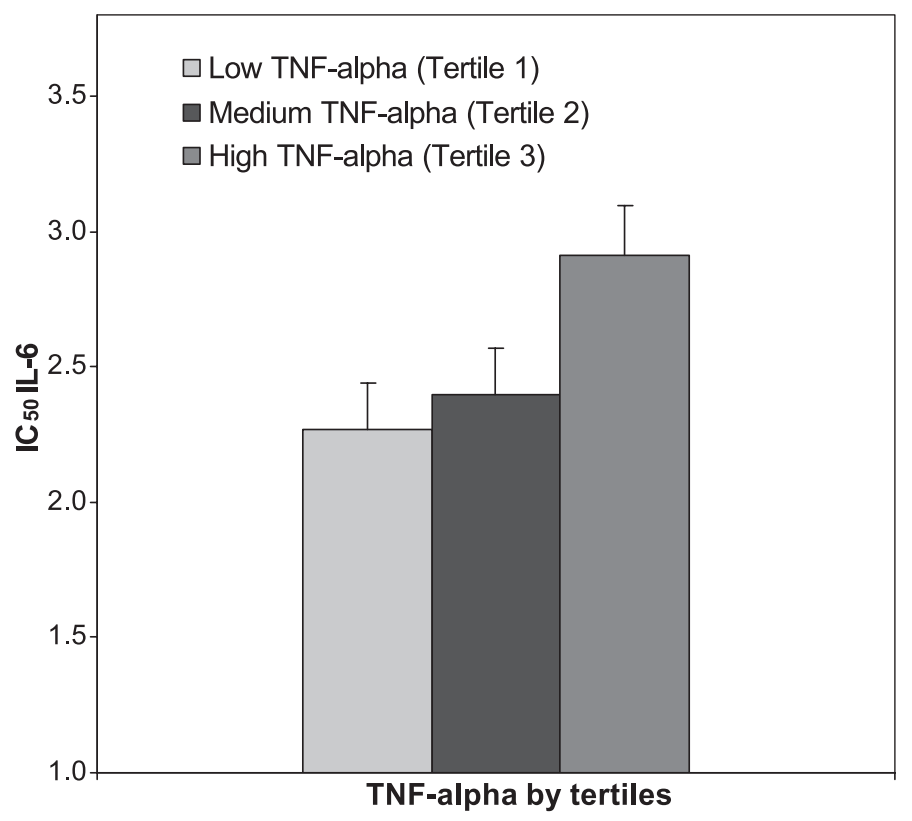

Fig. 2. Glucocorticoid sensitivity of LPS-stimulated release of interleukin-6 (IL-6) in the three groups. The IC ${ }_{50}$ is inversely related to glucocorticoid sensitivity; i.e., higher $\mathrm{IC}_{50}$ indicates lower glucocorticoid sensitivity. Subjects with high $\mathrm{TNF}-\alpha$ required relatively more dexamethasone to suppress LPS-stimulated IL-6 release than those with low $(\mathrm{p}=.028)$ and medium TNF- $\alpha(\mathrm{p}=.044)$. In other words, monocytes of subjects with higher basal inflammatory status as measured by plasma TNF- $\alpha$ were less sensitive to dexamethasone suppression of LPS-stimulated IL-6 secretion than monocytes of subjects with lower basal TNF- $\alpha$ levels. 
TNF- $\alpha$ as compared to those with medium TNF- $\alpha$ on the one hand, and between subjects with medium TNF- $\alpha$ as compared to those with low TNF- $\alpha$ on the other hand.

\section{Inhibition of stimulated cytokine production}

Fig. 1 shows the inhibition curve with IL-6 release plotted against increasing concentrations of dexamethasone. Curves were not different between groups $\left(\mathrm{F}_{5.4,453.1}=1.38, \mathrm{p}=.225\right.$; cardiovascular risk factors as covariates). Nonetheless, post-hoc tests showed reduced capacity of dexamethasone to inhibit IL-6 release in subjects with high TNF- $\alpha$ as compared to those with medium $(\mathrm{p}=.028)$ and with low TNF- $\alpha(\mathrm{p}=.010)$.

\section{Glucocorticoid sensitivity of cytokine production}

The $\mathrm{IC}_{50}$ of IL-6 differed between the groups $\left(\mathrm{F}_{2,167}=3.44, \mathrm{p}=.034\right.$; Fig. 2). Post-hoc comparisons revealed a dose-response relationship between basal TNF- $\alpha$ status and glucocorticoid sensitivity. Subjects with high TNF- $\alpha$ had higher $\mathrm{IC}_{50}$ of IL-6 than subjects with low $(\mathrm{p}=.014)$ and with medium TNF- $\alpha(p=.044)$. In other words, more dexamethasone was required to suppress IL-6 release in response to the same LPS stimulus in subjects of tertile 3 as compared to individuals in tertiles 1 and 2. Thus, men with high basal TNF- $\alpha$ had a lower monocyte glucocorticoid sensitivity than men with either low or medium TNF- $\alpha$ levels.

\section{Discussion}

In this study, we compared the monocyte glucocorticoid sensitivity in 224 working men stratified as per their basal TNF- $\alpha$-levels in plasma. We used an in-vitro assay to study monocyte IL-6 release in response to a standardized dose of LPS, and to assess the extent to which monocyte IL-6 release was inhibited by incremental concentrations of dexamethasone.

The main finding of our study is that men with high levels of plasma TNF- $\alpha$ required larger quantities of dexamethasone to inhibit LPS-stimulated release of IL-6 than those with lower plasma TNF- $\alpha$ levels. In addition, LPS-stimulated IL-6 release per cell without glucocorticoid inhibition was significantly higher in subjects with high TNF- $\alpha$. These findings suggest a higher pro-inflammatory activity in blood monocytes of men with high TNF- $\alpha$ than in those with lower TNF- $\alpha$. Of note this observation was not mediated by classic cardiovascular risk factors, which, to some extent, showed associations with TNF- $\alpha$ across groups.

Our findings suggest that circulating monocytes of subjects with high basal TNF- $\alpha$ have been primed by relatively higher TNF- $\alpha$ in vivo prior to being subjected to the in vitro LPS-condition resulting in exaggerated IL-6 response per monocyte. We speculate that, also in vivo, elevated TNF- $\alpha$ might enhance cytokine release from monocytes to any LPS-like danger signal (e.g., related to an infection or cellular stress), thereby promoting atherosclerosis. Epidemiological data support the notion that elevated plasma levels of both TNF- $\alpha$ and IL-6 increase the risk of coronary artery disease (Koukkunen et al., 2001; Ridker et al., 2000a). Thus, differential regulation of monocyte-IL-6 production may provide a link from acute inflammatory cytokine release $(\mathrm{TNF}-\alpha)$ to the long-term progression of atherosclerotic lesions. Our data suggest that monocytes from subjects with elevated TNF- $\alpha$ levels not only are kindled towards 
more pronounced IL-6 production but also that they are less sensitive to endogenous signals (glucocorticoids) responsible for curtailing inflammatory responses. This might lead to a more rapid development of atherosclerosis in individuals with elevated TNF- $\alpha$ levels (Koukkunen et al., 2001; Ridker et al., 2000b).

In contrast to our findings, previous in vivo studies reported either equal (Schafer et al., 1995) or decreased (Mikuniya et al., 1999; Pickup et al., 2000) IL-6 release after LPS stimulation in subjects with elevated compared to those with lower plasma levels of cytokines. However, those studies were conducted on relatively smaller sample sizes, and they included clinical populations with either defined diseases such as alcoholic liver cirrhosis (Schafer et al., 1995), type 2 diabetes (Pickup et al., 2000) or smoking-induced elevation in basal TNF- $\alpha$ levels (Mikuniya et al., 1999; Pickup et al., 2000). Consequently, findings from those studies may not be comparable with our observations in a working-population free of medication potentially affecting monocyte functioning. A carefully conducted in vitro study by Franchimont and co-workers also found less IL-6 secretion of whole blood cell cultures after LPS-stimulation when exposed to a comparatively high TNF- $\alpha$ dose $(1 \mathrm{ng} /$ $\mathrm{ml}$ ). However, in vivo TNF- $\alpha$ levels of our study participants were more than 300 -fold lower (see Table 1) than the in vitro concentration of TNF- $\alpha$ used in that study. We assume that these vastly different concentrations might account for the observed differences between our study and that study (Franchimont et al., 1999).

A possible explanation for reduced glucocorticoid sensitivity of monocytes in men with high plasma levels of TNF- $\alpha$ may relate to TNF- $\alpha$ induced reduction of functional glucocorticoid receptors (GR) on monocytes. Franchimont and coworkers showed that $48 \mathrm{~h}$ after exposure to TNF- $\alpha$, the number of GR receptors on monocytes decreased by $60 \%$ (Franchimont et al., 1999). On a cellular level, the development of a TNF- $\alpha$-mediated glucocorticoid resistance may relate to the activity of NF- $\kappa \mathrm{B}$ (Franchimont et al., 1999; Webster et al., 2001). NF-кB is highly expressed in inflamed tissues (Barnes and Karin, 1997), and it is also involved in the transcription of many proinflammatory cytokines (including IL-6) (Adcock and Caramori, 2001; Sapolsky et al., 2000). Mediated via a TNF-responsive NF-кB DNA binding site, GR $\beta$ mRNA increases to a greater extent than does GR $\alpha$ mRNA. The increase in GR $\beta$ protein expression correlates with the development of glucocorticoid resistance and a reduction in the number of functional GR receptors on the cell surface (Webster et al., 2001).

Several limitations of our study need to be addressed aside from self-reported history and medication use. First, our data are cross-sectional; therefore, they do not prove the sequence of events leading from elevated TNF- $\alpha$ to reduced monocyte glucocorticoid sensitivity. Second, our investigation focused on a working male population and thus, may not be generalizable to women, clinical populations and individuals with overt coronary artery disease in particular. Third, we can only speculate whether our observed differences between men with different basal TNF- $\alpha$ status are of clinical relevance in atherosclerotic diseases.

\section{Conclusion}

Our data suggest that monocytes of men with high basal inflammatory activity in vivo, as measured by plasma TNF- $\alpha$, show exaggerated proinflammatory reactivity to external LPS as well as reduced suppression of stimulated cytokine release by glucocorticoids. Such biological pathways may link proinflammatory cytokines to the pathogenesis of atherosclerosis and poor cardiovascular outcome. The 
clinical implications of our observations in health and cardiovascular disease remain to be demonstrated by the ongoing longitudinal follow-up of our participants.

\section{Acknowledgements}

This work was supported by grants from the EADS GmbH, Werk Augsburg, Germany, and from the Swiss Federal Institute of Technology, Zurich, Switzerland.

\section{References}

Adcock, I.M., Caramori, G., 2001. Cross-talk between pro-inflammatory transcription factors and glucocorticoids. Immunol. Cell Biol. 79, 376-384.

Barnes, P.J., Karin, M., 1997. Nuclear factor-kappaB: a pivotal transcription factor in chronic inflammatory diseases. N. Engl. J. Med. 336, 1066-1071.

Breuninger, L.M., Dempsey, W.L., Uhl, J., Murasko, D.M., 1993. Hydrocortisone regulation of interleukin-6 protein production by a purified population of human peripheral blood monocytes. Clin. Immunol. Immunopathol. 69, $205-214$.

Chrousos, G.P., 1995. The hypothalamic-pituitary-adrenal axis and immune-mediated inflammation. N. Engl. J. Med. 332, 1351-1362.

De Groote, D., Gevaert, Y., Lopez, M., Gathy, R., Fauchet, F., Dehart, I., Jadoul, M., Radoux, D., Franchimont, P., 1993. Novel method for the measurement of cytokine production by a one-stage procedure. J. Immunol. Methods 163, $259-267$.

De Groote, D., Zangerle, P.F., Gevaert, Y., Fassotte, M.F., Beguin, Y., Noizat-Pirenne, F., Pirenne, J., Gathy, R., Lopez, M., Dehart, I., et al., 1992. Direct stimulation of cytokines (IL-1 beta, TNF-alpha, IL-6, IL-2, IFN- gamma and GM-CSF) in whole blood: I. Comparison with isolated PBMC stimulation. Cytokine 4, 239-248.

DeRijk, R., Michelson, D., Karp, B., Petrides, J., Galliven, E., Deuster, P., Paciotti, G., Gold, P.W., Sternberg, E.M., 1997. Exercise and circadian rhythm-induced variations in plasma cortisol differentially regulate interleukin-1 beta (IL-1 beta), IL6, and tumor necrosis factor-alpha (TNF alpha) production in humans: high sensitivity of TNF alpha and resistance of IL-6. J. Clin. Endocrinol. Metab. 82, 2182-2191.

DeRijk, R.H., Petrides, J., Deuster, P., Gold, P.W., Sternberg, E.M., 1996. Changes in corticosteroid sensitivity of peripheral blood lymphocytes after strenous exercise in humans. Journal of Clinical Endocrinology and Metabolism $81,228-235$.

Elenkov, I.J., Wilder, R.L., Bakalov, V.K., Link, A.A., Dimitrov, M.A., Fisher, S., Crane, M., Kanik, K.S., Chrousos, G.P., 2001. IL-12, TNF-alpha, and hormonal changes during late pregnancy and early postpartum: implications for autoimmune disease activity during these times. J. Clin. Endocrinol. Metab. 86, 4933-4938.

Elkind, M.S., Cheng, J., Boden-Albala, B., Rundek, T., Thomas, J., Chen, H., Rabbani, L.E., Sacco, R.L., 2002. Tumor necrosis factor receptor levels are associated with carotid atherosclerosis. Stroke 33, 31-37.

Franchimont, D., Martens, H., Hagelstein, M.T., Louis, E., Dewe, W., Chrousos, G.P., Belaiche, J., Geenen, V., 1999. Tumor necrosis factor alpha decreases, and interleukin-10 increases, the sensitivity of human monocytes to dexamethasone: potential regulation of the glucocorticoid receptor. J. Clin. Endocrinol. Metab. 84, 2834-2839.

Heinrich, P.C., Castell, J.V., Andus, T., 1990. Interleukin-6 and the acute phase response. Biochem. J. 265 , $621-636$.

Jonsson, D., Rosengren, A., Dotevall, A., Lappas, G., Wilhelmsen, L., 1999. Job control, job demands and social support at work in relation to cardiovascular risk factors in MONICA 1995, Goteborg. J. Cardiovasc. Risk 6, 379-385.

Koukkunen, H., Penttila, K., Kemppainen, A., Halinen, M., Penttila, I., Rantanen, T., Pyorala, K., 2001. C-reactive protein, fibrinogen, interleukin-6 and tumour necrosis factor-alpha in the prognostic classification of unstable angina pectoris. Ann. Med. 33, 37-47.

Michael, Y.L., Colditz, G.A., Coakley, E., Kawachi, I., 1999. Health behaviors, social networks, and healthy aging: crosssectional evidence from the Nurses' Health Study. Qual. Life Res. 8, 711-722.

Mikuniya, T., Nagai, S., Tsutsumi, T., Morita, K., Mio, T., Satake, N., Izumi, T., 1999. Proinflammatory or regulatory cytokines released from BALF macrophages of healthy smokers. Respiration 66, 419-426. 
Pickup, J.C., Chusney, G.D., Thomas, S.M., Burt, D., 2000. Plasma interleukin-6, tumour necrosis factor alpha and blood cytokine production in type 2 diabetes. Life Sci. 67, 291-300.

Plutzky, J., 2001. Inflammatory pathways in atherosclerosis and acute coronary syndromes. Am. J. Cardiol. 88, 10K-15K.

Ridker, P.M., Rifai, N., Stampfer, M.J., Hennekens, C.H., 2000a. Plasma concentration of interleukin-6 and the risk of future myocardial infarction among apparently healthy men. Circulation 101, 1767-1772.

Ridker, P.M., Rifai, N., Pfeffer, M., Sacks, F., Lepage, S., Braunwald, E., 2000b. Elevation of tumor necrosis factor-alpha and increased risk of recurrent coronary events after myocardial infarction. Circulation 101, 2149-2153.

Rohde, L.E., Arroyo, L.H., Rifai, N., Creager, M.A., Libby, P., Ridker, P.M., Lee, R.T., 1999. Plasma concentrations of interleukin-6 and abdominal aortic diameter among subjects without aortic dilatation. Arterioscler. Thromb. Vasc. Biol. 19, 1695-1699.

Rohleder, N., Schommer, N.C., Hellhammer, D.H., Engel, R., Kirschbaum, C., 2001. Sex differences in glucocorticoid sensitivity of proinflammatory cytokine production after psychosocial stress. Psychosom. Med. 63, 966-972.

Ross, R., 1999. Atherosclerosis - an inflammatory disease. N. Engl. J. Med. 340, 115-126.

Sapolsky, R.M., Romero, L.M., Munck, A.U., 2000. How do glucocorticoids influence stress responses? Integrating permissive, suppressive, stimulatory, and preparative actions. Endocr. Rev. 21, 55-89.

Schafer, C., Schips, I., Landig, J., Bode, J.C., Bode, C., 1995. Tumor-necrosis-factor and interleukin-6 response of peripheral blood monocytes to low concentrations of lipopolysaccharide in patients with alcoholic liver disease. Z. Gastroenterol. 33, 503-508.

Schnorpfeil, P., Noll, A., Wirtz, P., Schulze, R., Ehlert, U., Frey, K., Fischer, J.E., 2002. Assessment of exhaustion and related risk factors in employees in the manufacturing industry-a cross-sectional study. Int. Arch. Occup. Environ. Health 75 , 535-540.

Seeman, T.E., Singer, B.H., Rowe, J.W., Horwitz, R.I., McEwen, B.S., 1997. Price of adaptation-allostatic load and its health consequences. MacArthur studies of successful aging. Arch. Intern. Med. 157, 2259-2268.

Vaddi, K., Nicolini, F.A., Mehta, P., Mehta, J.L., 1994. Increased secretion of tumor necrosis factor-alpha and interferon-gamma by mononuclear leukocytes in patients with ischemic heart disease. Relevance in superoxide anion generation. Circulation 90, 694-699.

Webster, J.C., Oakley, R.H., Jewell, C.M., Cidlowski, J.A., 2001. Proinflammatory cytokines regulate human glucocorticoid receptor gene expression and lead to the accumulation of the dominant negative beta isoform: a mechanism for the generation of glucocorticoid resistance. Proc. Natl. Acad. Sci. U. S. A. 98, 6865-6870.

Wick, G., Hu, Y., Schwarz, S., Kroemer, G., 1993. Immunoendocrine communication via the hypothalamo-pituitary-adrenal axis in autoimmune diseases. Endocr. Rev. 14, 539-563.

Wright, S.D., Ramos, R.A., Tobias, P.S., Ulevitch, R.J., Mathison, J.C., 1990. CD14, a receptor for complexes of lipopolysaccharide (LPS) and LPS binding protein. Science 249, 1431-1433.

Yudkin, J.S., Kumari, M., Humphries, S.E., Mohamed-Ali, V., 2000. Inflammation, obesity, stress and coronary heart disease: is interleukin-6 the link? Atherosclerosis 148, 209-214. 